\title{
Michigan Pharmacists Transforming Care and Quality: Developing a Statewide Collaborative of Physician Organizations and Pharmacists to Improve Quality of Care and Reduce Costs
}

\author{
Hae Mi Choe, PharmD; Alexandra Tungol Lin, PharmD; Kathleen Kobernik, RPCV; Marc Cohen, MHSA; \\ Laurie Wesolowicz, PharmD, FAMCP; Nabeel Qureshi, PharmD, MPH; Tom Leyden, MBA; \\ David A. Share, MD; Rozanne Darland, BSBA; and David A. Spahlinger, MD
}

\begin{abstract}
BACKGROUND: Inappropriate drug use, increasing complexity of drug regimens, continued pressure to control costs, and focus on shared accountability for clinical measures drive the need to leverage the medication expertise of pharmacists in direct patient care. A statewide strategy based on the collaboration of pharmacists and physicians regarding patient care was developed to improve disease state management and medicationrelated outcomes.

PROGRAM DESCRIPTION: Blue Cross Blue Shield of Michigan (BCBSM) partnered with Michigan Medicine to develop and implement a statewide provider-payer program called Michigan Pharmacists Transforming Care and Quality (MPTCQ), which integrates pharmacists within physician practices throughout the state of Michigan. As the MPTCQ Coordinating Center, Michigan Medicine established an infrastructure integrating clinical pharmacists into direct patient care within patient-centered medical home (PCMH) practices and provides direction and guidance for quality and process improvement across physician organizations (POs) and their affiliated physician practices. The primary goal of MPTCQ is to improve patient care and outcomes related to Medicare star ratings and HEDIS measures through integration of clinical pharmacists into direct patient care. The short-term goal is to adopt and modify Michigan Medicine's integrated pharmacist practice model at participating P0s, with the long-term goal of developing a sustainable model of pharmacist integration at each PO to improve patient care and outcomes. Initially, pharmacists are delivering disease management (diabetes, hypertension, and hyperlipidemia) and comprehensive medication review services with future plans to expand clinical services.
\end{abstract}

OBSERVATIONS: In 2015, 10 POs participated in year 1 of the program. In collaboration with the MPTCQ Coordinating Center, each PO identified 1 "pharmacist transformation champion" (PTC). The PTC implemented the integrated pharmacist model at 2 or 3 practice sites with at least 2 practicing physicians per site.

IMPLICATIONS: MPTCQ is a unique collaboration between a large academic institution, physician organizations, a payer, and a statewide coordinating center to improve patient care and address medication-related challenges by integrating pharmacists into a PCMH network. Pharmacists can actively provide their medication expertise to physicians and patients and optimize quality measure performance.

J Manag Care Spec Pharm. 2018;24(4):373-78

Copyright $\odot 2018$, Academy of Managed Care Pharmacy. All rights reserved.
T he health care delivery model in the United States is rapidly evolving to reduce health care expenditures, improve quality of care, and enhance the patient experience. ${ }^{1}$ Such transformation will be measured in part by quality measures that commercial and Medicare insurers must report in order to participate in government-sponsored health plans, including Healthcare Effectiveness Data and Information Set (HEDIS), Medicare star ratings, and the Marketplace Quality Rating System. These quality measures include medicationrelated chronic disease scoring, such as adherence to medications for diabetes, hypertension, and hyperlipidemia. With a shortage of 12,500-31,100 primary care physicians (PCPs) expected by 2025, clinical pharmacists can support physicians by providing more advanced patient care management, such as medication and disease management. ${ }^{2}$ An effective strategy being adopted by the primary care community to address quality, access to care, and health care costs is a multidisciplinary, team-based care model known as the patient-centered medical home (PCMH), in which clinical pharmacists can be integrated as valuable contributors of the patient-care team.

According to the Centers for Disease Control and Prevention, among Americans aged 55-64 years, 55.6\% take 1 to 4 prescription medications, and $20.3 \%$ take 5 or more. ${ }^{3}$ With clinical pharmacists reviewing all medications (prescription, overthe-counter, vitamins, and supplements) to ensure efficacy, safety, and cost-effectiveness as the standard of care, the needs of patients for better disease control and ongoing medication management can be met. Optimal medication use is critical in producing positive outcomes in chronic conditions, yet only approximately $50 \%$ of patients take their medications as prescribed. ${ }^{4}$ The involvement of clinical pharmacists in primary care teams has been shown to significantly improve medication adherence..$^{5-7}$ Working closely with physicians and patients, clinical pharmacists who understand the complexity of medication use can assess treatment burden versus treatment needs and devise affordable therapeutic plans for patients.

Collaborating with clinical pharmacists has a positive effect on several chronic conditions, including hypertension and diabetes. ${ }^{8}$ A pharmacist-physician collaboration in hypertension management achieved consistent and significantly greater reduction in 24-hour systolic blood pressure compared with 
the control group (14.1 vs. $5.5 \mathrm{mmHg}, P<0.001) .{ }^{9}$ More patients receiving a pharmacist intervention achieved blood pressure control within the study period compared with the control group $(75.0 \%$ vs. $50.7 \%, P<0.001) .{ }^{9}$ Patients who received care from a clinical pharmacist who evaluated and modified drug therapy achieved greater reduction in hemoglobin Alc (Alc) than the control group $(2.1 \%$ vs. $0.9 \%, P=0.030) .{ }^{10}$

Pharmacists who provided face-to-face appointments with patients in a PCP office setting were able to identify 3,248 drug discrepancies and 917 drug-related problems (10.4 problems per patient) during a 1-year study period. ${ }^{11}$ Pharmacist appointments consisted of comprehensive medication histories to identify and resolve drug-related problems for patients with over 5 medical conditions who took 15.7 drugs per day, on average. In total, $78 \%$ of problems were resolved without the patient needing an additional PCP appointment. Estimated annual savings were $\$ 1,123$ per patient in medication claims. ${ }^{11}$

\section{Proposed Solution: Integration of Pharmacists Within Physician Practices in a Statewide Provider-Payer Partnership}

A cost analysis by Fitch et al. (2013) found that better control of Alc, blood pressure, and lipids is associated with cost savings for patients with diabetes by reducing complications. ${ }^{12}$ In the commercially insured population, cost savings across all patients with diabetes ranged from $\$ 67$ to $\$ 105$ per patient per month by improving Alc (1.0\%-1.5\%), systolic blood pressure (10-30 mmHg), and high-density lipoprotein/total cholesterol (20\%-50\%). For every 1,000 patients who achieved better control of these conditions, potential savings would be $\$ 804,000$ to $\$ 1,260,000$ per year. ${ }^{12}$ The objective of this article is to describe the development and implementation of the Michigan Pharmacists Transforming Care and Quality (MPTCQ) program across the state of Michigan. Subsequent analysis of outcomes will be collected and reported in the future.

\section{Program Description}

\section{Nationally Recognized Best Practice Model: Michigan Medicine}

The ambulatory care clinical pharmacists have been successfully integrated into Michigan Medicine for over 8 years. Michigan Medicine has a positive model for team-based care using clinical pharmacists to improve disease control and optimize medication-related outcomes. In 2011, the Michigan Medicine pharmacist practice model was selected for the Innovative Pharmacy Practice Award from the Michigan Pharmacists Association and the Best Practice Award from the American Society of Health-System Pharmacists. ${ }^{13,14}$ In December 2014, Michigan Medicine was highlighted and profiled as 1 of 5 best integrated pharmacy practice models in the nation by The Advisory Board Company. ${ }^{15}$
At Michigan Medicine, 11 clinical pharmacists (equal to 5.2 full-time equivalents) are embedded in ambulatory care clinics as integral members of the patient care team across 14 primary care sites. These clinical pharmacists provide disease management services for patients with diabetes, hypertension, and hyperlipidemia and comprehensive medication review for patients with medication-related problems. Proactive outreach by these clinical pharmacists, who have close working relationships with patient physicians, increase patient interest and engagement in the services. Integrating clinical pharmacists in the primary care clinics allows full access to electronic medical records (EMR), including medication and laboratory data. In addition to EMR access, a meaningful collaborative practice agreement and bidirectional communication between providers are essential in providing high-quality care.

At provider or patient request, clinical pharmacists complete assessments of cost-saving opportunities. These interventions can reduce patient out-of-pocket and payer medication costs, maintain therapeutic effectiveness, and enhance medication adherence. While clinical pharmacists actively work with patients to achieve treatment goals, improve adherence, and provide education, they also closely monitor disease-specific gaps in care for individual patients (e.g., diabetic foot exams and screening for nephropathy). Clinical pharmacists also address gaps in care at a population level (e.g., improving statin use in patients with diabetes) by proactively identifying patients using disease registries and reaching out to those patients.

\section{Blue Cross Blue Shield of Michigan's Value Partnerships Program}

Blue Cross Blue Shield of Michigan's Value Partnerships program is a collection of statewide health care collaborations with physicians and hospitals that are transforming the delivery and quality of patient care throughout Michigan. Value Partnerships has created a network of more than 40 physician organizations (POs) that represent nearly 20,000 primary care and specialist physicians who serve 2 million Michigan Blue Cross members. Blue Cross Blue Shield of Michigan (BCBSM) and these POs partnered to create natural communities of caregivers with sufficient leadership, administrative structure, and technical expertise to support integrated information systems and shared processes of care. Established in 2005, the Value Partnerships program offers an innovative approach to provider reimbursement, shifting from the traditional fee-for-service model to a fee-for-value model. One of Value Partnerships' largest programs is the Physician Group Incentive Program (PGIP). From 2008 to 2011, PGIP lowered total spending among 3 million beneficiaries by approximately 1.1\% for adults and improved or maintained performance on 11 of 14 quality measures. ${ }^{16}$ MPTCQ's strategic vision and direction further promotes PGIP's commitment to transform care. 


\section{TABLE 1 Data Metrics to be Collected for Quality Measures that MPTCQ Can Support}

\begin{tabular}{|c|c|c|c|}
\hline Pharmacy-Related Quality Measures & $\mathrm{QRS}^{20}$ & HEDIS 20,21 & $\begin{array}{c}\text { Medicare Star } \\
\text { Ratings }^{21-23}\end{array}$ \\
\hline \multicolumn{4}{|l|}{ Treatment goals } \\
\hline Comprehensive diabetes care: hemoglobin Alc (HbAlc) control $(<8.0 \%)$ & $\checkmark$ & $\sqrt{a, b}$ & $\sqrt{ } \mathrm{c}$ \\
\hline Comprehensive diabetes care: hemoglobin Alc (HbAlc) testing & $\checkmark$ & & \\
\hline Comprehensive diabetes care: eye exam (retinal) performedd & $\checkmark$ & $\sqrt{ } \mathrm{a}, \mathrm{b}$ & $\checkmark$ \\
\hline Comprehensive diabetes care: medical attention for nephropathyd & $\checkmark$ & $\sqrt{ } \mathrm{a}, \mathrm{b}$ & $\checkmark$ \\
\hline Controlling high blood pressure & $\checkmark$ & $\sqrt{ } \mathrm{a}, \mathrm{b}$ & $\checkmark$ \\
\hline \multicolumn{4}{|l|}{ Medication adherence } \\
\hline Proportion of days covered (diabetes, RAS antagonists, statins) & $\checkmark$ & & $\checkmark$ \\
\hline \multicolumn{4}{|l|}{ Safety } \\
\hline Annual monitoring for patients on persistent medications & $\checkmark$ & & \\
\hline \multicolumn{4}{|l|}{ Evidence-based medication use } \\
\hline Statin use in persons with diabetes & & & $\sqrt{ } \mathrm{e}$ \\
\hline \multicolumn{4}{|c|}{$\begin{array}{l}\text { aHEDIS measure required for NCQA accreditation of commercial health plans. } \\
\text { bHEDIS measure required for NCQA accreditation of Medicare health plans. } \\
\text { 'Star ratings measure evaluates for Alc control }(\leq 9.0 \%) \text {. } \\
\text { dPharmacists can assist with eye exam and nephropathy measures by identifying patients who need further attention through one-on-one appointments and provide } \\
\text { referral as needed. } \\
\text { eProposed as } 2019 \text { star ratings measure (using } 2017 \text { data). } \\
\text { Alc=hemoglobin Alc; HEDIS = Healthcare Effectiveness Data and Information Set; MPTCQ= Michigan Pharmacists Transforming Care and Quality; NCQA=National } \\
\text { Committee for Quality Assurance; QRS = Quality Rating System; RAS=renin angiotensin system. }\end{array}$} \\
\hline
\end{tabular}

\section{Collaborative Quality Initiatives and Collaborative Process Initiatives}

Collaborative Quality Initiatives (CQIs) are statewide quality improvement initiatives that have been developed and executed by Michigan physicians and hospital partners, with support from BCBSM and its health maintenance organization affiliate Blue Care Network (for hospital CQIs). CQIs support development of best practices for areas of care that are highly technical, medically complex, and rapidly evolving. The focus of MPTCQ is a select set of care processes that are already known to yield good outcomes, and it strives to systematically implement those processes so is considered a Collaborative Process Initiative (CPI).

The coordinating center plays an integral role in providing guidance, leadership, tools, and resources and coordinates the rapid dissemination of information and sharing of best practices to improve clinical processes and outcomes. BCBSM works in collaboration with the coordinating centers to support organizations that are participating in each program. Each coordinating center is led by a Michigan-based clinical program director who is a respected expert in the clinical area of focus and has extensive experience in leading quality or process improvement initiatives, along with a program manager and staff to administer the program's daily activities.

\section{Creating Partnerships Between Michigan Medicine and BCBSM}

Michigan Medicine's expertise in leading statewide provider initiatives and experience with this creative pharmacist model made it a strong partner in developing a statewide providerpayer program that integrates pharmacists within physician practices. BCBSM partnered with Michigan Medicine to implement MPTCQ, with Michigan Medicine serving as the coordinating center. The MPTCQ Coordinating Center has established an infrastructure that integrates clinical pharmacists in direct patient care within PCMH practices and provides direction and guidance for quality and process improvement across POs and their affiliated physician practices. MPTCQ drives clinical content and priorities, operations, training (pharmacist and PO leadership), and data collection and evaluation. BCBSM provides financial support and guidance on the CPI approach.

\section{Value Proposition of MPTCQ in Improving Patient Care Across Michigan}

Pharmacists embedded within POs already play multiple roles. Evidencehas shown that an integrated care modelallows pharmacists to help improve patient care through pharmacist-physician collaboration. The MPTCQ program is a good fit with PGIP, since affiliated physicians affect care that is provided to all Michigan residents.

Pharmacists in MPTCQ are trained to provide direct patient care through a strong collaborative relationship with physicians and provide continuous support in expanding the integrated care model with the goal of ultimately enhancing clinical care and improving quality. A strong collaborative relationship between pharmacists and physicians increases acceptance by physicians of therapeutic recommendations made by 
pharmacists. ${ }^{17-19}$ The physician-pharmacist team can efficiently and effectively address many targeted quality measures, especially those that are related to medication. Clinical pharmacists who perform comprehensive medication and disease management services in this team-based model provide an array of patient care support so that issues related to disease and medication can be addressed, such as treatment goals, adherence, medication costs, education, and gaps in care.

\section{Goals and Objectives}

The primary goal of MPTCQ is to improve patient care and outcomes through integration of clinical pharmacists in direct patient care. Through this integration, improvements in performance are expected for several quality and process-related measures. The short-term goal is to adopt and modify the Michigan Medicine integrated pharmacist practice model at the participating POs. The long-term goal is to develop a sustainable model of pharmacist integration at each PO for the improvement of patient care and outcomes.

\section{Pharmacist Services}

With direction and guidance from the MPTCQ Coordinating Center, the initial focus of the pharmacist care component is to deliver disease management (diabetes, hypertension, and hyperlipidemia) and comprehensive medication review services. After successful implementation of initial services, the program will expand to include other chronic conditions (e.g., behavioral health), transitions of care, and telehealth.

\section{Evaluation Design and Data Analysis}

Integrating clinical pharmacists in POs to provide advanced patient care management supports the quality measures for which commercial and Medicare insurers are held accountable (Table 1). These quality metrics were selected based on payer priorities. Various process and clinical data elements are collected and evaluated to measure successful integration of pharmacists within the POs by examining program impact on these nationally accepted measures.

\section{Observations}

Beginning on November 1, 2015, year 1 implementation of the MPTCQ program included initial recruitment of $10 \mathrm{POs}$ (including at least 2 primary care practice sites per $\mathrm{PO}$ ) with the intent to include the remaining POs over subsequent years. The initial 10 eligible POs were recruited based on eligibility criteria that included a readiness assessment survey and demonstration of adequate $\mathrm{PO}$ and practice site infrastructure to support this initiative. Examples of interest and infrastructure included letters of support and interest from PO medical leadership, available office space and work areas for clinical pharmacists, ability to provide staff support, and a signed collaborative practice agreement. Geographic diversity and types of practices within the POs (e.g., academic or community, employed or independent) were also considered for year 1 participation. Successful adoption and implementation of the integrated pharmacist model at these 10 POs was important to solidify the MPTCQ proposed goals and objectives.

In collaboration with the MPTCQ Coordinating Center, each PO identified 1 "pharmacist transformation champion" (PTC). The PTC implemented the integrated pharmacist model at 2 or 3 practice sites, with at least 2 practicing physicians per site. These practice sites previously did not have a clinical pharmacist on-site. As the program matures and POs find increasing value in pharmacist contributions, each $\mathrm{PO}$ will be expected to support continued participation by billing for the pharmacist's part of direct patient care and receiving financial rewards for improvement in quality metrics and to continue building infrastructure by adding clinical pharmacists and expanding the integrated model across their remaining practice sites (Figure 1).

Some of the participating POs have multiple small private practices where embedding a pharmacist even a half day a week may not seem feasible. After successful integration of clinical pharmacy services at some of the larger physician practices, the PTC can collaborate with PO leadership on creating a plan (e.g., central or regional model) to meet these unique needs. Having experienced and trained PTCs who 
understand operational and structural challenges of their own POs provides the expertise and engagement needed to build an enhanced care delivery model.

\section{Data Collection}

An intervention checklist was developed to standardize the data collection process and to capture pertinent clinical interventions provided by the pharmacists during patient encounters. The MPTCQ Coordinating Center has developed a centralized web-based data registry to collect data from all participating practice sites and monitor improvements in outcomes. Pharmacists enter data as part of their workflow, with documentation taking about 3 minutes per encounter. When pharmacists have issues with data entry, the coordinating center provides the information technology support.

\section{Training}

The MPTCQ training includes an annual 2-day PTC Boot Camp, quarterly pharmacist meetings, and annual strategic planning meetings that involves PO clinical and administrative leadership. PTCs also participate in monthly mentoring calls with the coordinating center team to ensure that program milestones are met and to receive guidance on practice development. To provide clinical support for the PTCs, a coordinating center clinical pharmacist conducts a weekly conference call to discuss difficult patient cases.

\section{Staff Resource Utilization Model for POs and Expected Participation Costs}

Participating POs receive BCBSM support for 2 years in order to establish a PTC position. This individual supports implementation of the integrated pharmacist practice model as defined by the MPTCQ Coordinating Center. Since most POs are new to the integrated pharmacist model, BCBSM's support encourages and incentivizes POs to invest in building this practice model. As the program matures over the 2 years, participation-based support will transition to pay-for-performance.

\section{Implications}

Clinical quality has become an increasingly important component of the health care system. Health plans and health care providers are held accountable for providing quality health care services, resulting in the change from fee-for-service to value-based payment. Pharmacist expertise supports the optimization of performance on medication-related quality measures, while also addressing rising drug costs. Pharmacists can actively provide their medication expertise to physicians and patients and maximize the value of pharmaceutical-based care.

A partnership between POs and their providers, the payer, and a statewide coordinating center fosters a close collaboration between key stakeholders to improve patient care and outcomes. The MPTCQ Coordinating Center facilitates collaboration between PTCs across the state to share best practices and tools to optimize clinical practices. This model warrants broader implementation and evaluation because it offers the potential to meaningfully address current and future medication-related challenges that are faced by physicians, pharmacists, payers, and patients.

\section{Authors}

HAE MI CHOE, PharmD, Pharmacy Innovations \& Partnerships, University of Michigan Medical Group, and University of Michigan College of Pharmacy, Ann Arbor. ALEXANDRA TUNGOL LIN, PharmD; KATHLEEN KOBERNIK, RPCV; MARC COHEN, MHSA; LAURIE WESOLOWICZ, PharmD, FAMCP; NABEEL QURESHI, PharmD, MPH; TOM LEYDEN, MBA; DAVID A. SHARE, MD; and ROZANNE DARLAND, BSBA, Blue Cross Blue Shield of Michigan, Detroit. DAVID A. SPAHLINGER, MD, University of Michigan Medical School, Ann Arbor.

AUTHOR CORRESPONDENCE: Hae Mi Choe, PharmD, Pharmacy Innovations \& Partnerships, University of Michigan Medical Group, and Clinical Associate Professor, University of Michigan College of Pharmacy, UMHS, 1301 Catherine St., 6312 Med Sci I, Ann Arbor, MI 48109-5693. Tel.: 734.764.4763; E-mail: haemi@med.umich.edu.

\section{DISCLOSURES}

This project was funded by Blue Cross Blue Shield of Michigan. Choe and Spahlinger are employees of Michigan Medicine. Tungol Lin, Kobernik, Cohen, Qureshi, Leyden, and Darland are employees of Blue Cross Blue Shield of Michigan. At the time of manuscript preparation, Share and Wesolowicz were employees of Blue Cross Blue Shield of Michigan.

Study concept and design were primarily contributed by Choe, along with the other authors. Choe, Tungol Lin, and Kobernik collected data, and data interpretation was performed by Choe, Tungol Lin, Cohen, and Wesolowicz. The manuscript was written primarily by Choe, along with Tungol Lin and assisted by Kobernik, Cohen, Leyden, and Qureshi. The manuscript was revised by Leyden, Spahlinger, Share, and Darland.

Material from this manuscript was previously presented as an education session at the 2016 AMCP Managed Care \& Specialty Pharmacy Annual Meeting; April 19-22, 2016; San Francisco, California.

\section{REFERENCES}

1. Institute for Healthcare Improvement. IHI triple aim initiative. 2017. Available at: http://www.ihi.org/Engage/Initiatives/TripleAim/Pages/default. aspx. Accessed March 8, 2018.

2. Dall T, West T, Chakrabarti R, Iacobucci W. The complexities of physician supply and demand: projections from 2013 to 2025. Final report. Prepared for the Association of American Medical Colleges. 2015. Available at: https:// www.aamc.org/download/426242/data/ihsreportdownload.pdf. Accessed March 8, 2018.

3. National Center for Health Statistics. Health, United States, 2014: with special feature on adults aged 55-64. May 2015. Available at: http://www cdc.gov/nchs/data/hus/hus14.pdf. Accessed March 8, 2018

4. Brown MT, Bussell JK. Medication adherence: WHO cares? Mayo Clin Proc 2011;86(4):304-14. Available at: http://www.ncbi.nlm.nih.gov/pmc/articles/ PMC3068890/pdf/mayoclinproc_86_4_007.pdf. Accessed March 8, 2018. 


\section{Michigan Pharmacists Transforming Care and Quality: Developing a Statewide Collaborative of Physician Organizations and Pharmacists to Improve Quality of Care and Reduce Costs}

5. Sharaya NH, Dorrell MF, Sciacca NA. The impact of addressing adherence in pharmacist-managed pharmacotherapy clinics. J Pharm Pract. 2017;30(1):37-41

6. Lee JK, Grace KA, Taylor AJ. Effect of a pharmacy care program on medication adherence and persistence, blood pressure, and low-density lipoprotein cholesterol: a randomized controlled trial. JAMA. 2006;296(21):2563-71. Available at: http://jama.jamanetwork.com/article.aspx?articleid=204402\&re sultclick=1. Accessed March 8, 2018.

7. Murray MD, Young J, Hoke S, Tu W, Weiner M, Morrow D, et al. Pharmacist intervention to improve medication adherence in heart failure: a randomized trial. Ann Intern Med. 2007;146(10):714-25.

8. Chisholm-Burns MA, Kim Lee J, Spivey CA, et al. US pharmacists' effect as team members on patient care: systematic review and meta-analyses. Med Care. 2010;48(10):923-33.

9. Weber CA, Ernst ME, Sezate GS, Zheng S, Carter BL. Pharmacistphysician comanagement of hypertension and reduction in 24-hour ambulatory blood pressures. Arch Intern Med. 2010;170(18):1634-39. Available at: http://archinte.jamanetwork.com/article.aspx?articleid=226073. Accessed March 8, 2018

10. Choe HM, Mitrovich S, Dubay D, Hayward RA, Krein SL, Vijan S. Proactive case management of high-risk patients with type 2 diabetes mellitus by a clinical pharmacist: a randomized controlled trial. Am J Manag Care. 2005;11(4):253-60. Available at: http://www.ajmc.com/journals/ issue/2005/2005-04-voll1-n4/Apr05-2017p0253-0260/. Accessed March 8, 2018.

11. Smith M, Giuliano MR, Starkowski MP. In Connecticut: improving patient medication management in primary care. Health Aff (Millwood). 2011;30(4):646-54. Available at: https://www.healthaffairs.org/doi/ full/10.1377/hlthaff.2011.0002. Accessed March 8, 2018.

12. Fitch K, Pyenson BS, Iwasaki K. Medical claim impact of improved diabetes control for Medicare and commercially insured patients with type 2 diabetes. J Manag Care Pharm. 2013;19(8):609-20. Available at: https://www. jmcp.org/doi/10.18553/jmcp.2013.19.8.609. Accessed March 8, 2018.

13. Choe HM, Rockafellow S, Wells T, et al. Patient centered medical home: developing, expanding and sustaining a role for pharmacists. Poster presented at: ASHP 2011 Summer Meeting; June 12-15, 2011; Denver, CO. Available at: http://www.ashpadvantage.com/bestpractices/2011_papers/Posters/ Michigan.pdf. Accessed March 8, 2018.
14. Michigan Pharmacists Association. Michigan Pharmacists Association awards: previous recipients. Available at: http://www.michiganpharmacists. org/Portals/0/mpa/awards/previousrecipients_2017v2.pdf. Accessed March 8, 2018.

15. Advisory Board. Integrated pharmacy models in primary care. Executive research briefing. December 22, 2014. Available at: https://www.advisory. $\mathrm{com} /$ research/population-health-advisor/white-papers/2014/integratedpharmacy-models-in-primary-care. Accessed March 8, 2018.

16. Lemak CH, Nahra TA, Cohen GR, et al. Michigan's fee-for-value physician incentive program reduces spending and improves quality in primary care. Health Aff (Millwood). 2015;34(4):645-52.

17. Haxby DG, Weart CW, Goodman BW Jr. Family practice physicians' perceptions of the usefulness of drug therapy recommendations from clinical pharmacists. Am J Hosp Pharm. 1988;45(4):824-27.

18. Von Muenster SJ, Carter BL, Weber CA, et al. Description of pharmacist interventions during physician-pharmacist co-management of hypertension. Pharm World Sci. 2008;30(1):128-35.

19. Galt KA. Cost avoidance, acceptance, and outcomes associated with a pharmacotherapy consult clinic in a Veterans Affairs Medical Center. Pharmacotherapy. 1998;18(5):1103-11.

20. Centers for Medicare $\&$ Medicaid Services. Quality rating system measure technical specifications. September 2015. Available at: https://www. cms.gov/Medicare/Quality-Initiatives-Patient-Assessment-Instruments/ QualityInitiativesGenInfo/Downloads/2016-QRS-Measure-TechnicalSpecifications.pdf. Accessed March 8, 2018

21. National Committee for Quality Assurance. HEDIS 2016. 2015. Available at: http://www.ncqa.org/hedis-quality-measurement/hedis-measures/hedis2016. Accessed March 8, 2018.

22. Centers for Medicare \& Medicaid Services. Medicare 2016 Part C \& D star rating technical notes. First plan preview. Updated August 5, 2015. Available at: https://www.cms.gov/Medicare/Prescription-Drug-Coverage/ PrescriptionDrugCovGenIn/Downloads/2016-Technical-Notes-Preview1-v2015_08_05.pdf. Accessed March 8, 2018.

23. Centers for Medicare \& Medicaid Services. Advance notice of methodological changes for calendar year (CY) 2017 for Medicare Advantage (MA) capitation rates, Part C and Part D payment policies and 2017 call letter. February 19, 2016. Available at: https://www.cms.gov/Medicare/HealthPlans/MedicareAdvtgSpecRateStats/Downloads/Advance2017.pdf. Accessed March 8, 2018. 